\title{
Air-Sea Interaction in the Southern Ocean: Exploring the Height of the Wave Boundary Layer at the Air-Sea Interface
}

\section{Alejandro Cifuentes-Lorenzen ${ }^{1}$ (D) James B. Edson ${ }^{2} \cdot$ Christopher J. Zappa $^{3}$}

Received: 11 September 2017 / Accepted: 26 June 2018

(c) Springer Nature B.V. 2018

\begin{abstract}
We investigate the momentum and energy exchange across the wave boundary layer (WBL). Directly at the air-sea interface, we test three wave-growth parametrizations by comparing estimates of the wave-induced momentum flux derived from wave spectra with direct covariance estimates of the momentum flux. An exponential decay is used to describe the vertical structure of the wave-induced momentum in the atmospheric WBL through use of a decay rate, a function of the dimensionless decay rate and wavenumber $(A=\alpha k)$. The decay rate is varied to minimize the difference between the energy extracted from the WBL and the energy flux computed from wave spectra using our preferred wave-growth parametrization. For wave ages (i.e. the peak phase speed to atmospheric friction velocity ratio) in the range $15<c_{p} / u_{*}<35$ we are able to balance these two estimates to within $10 \%$. The decay rate is used to approximate the WBL height as the height to which the wave-induced flux is 0.1 of its surface value and the WBL height determined this way is found to be between 1-3 $\mathrm{m}$. Finally, we define an effective phase speed with which to parametrize the energy flux for comparison with earlier work, which we ultimately attempt to parametrize as a function of wind forcing.
\end{abstract}

Keywords Air-sea interaction · Effective phase speed · Wave boundary layer

\section{Introduction}

Over the ocean, the exchange of momentum and energy across the air-sea interface is modulated by the existence of a feedback between the wind and the waves. The feedback mechanisms between the wind and wave fields are at the core of air-sea interaction, where

\section{Alejandro Cifuentes-Lorenzen}

alejandro.cifuentes@uconn.edu

1 Department of Marine Sciences, University of Connecticut, Storrs, CT 06340, USA

2 Applied Ocean Physics, and Engineering, Woods Hole Oceanographic Institution, Woods Hole, MA 02543, USA

3 Ocean and Climate Physics, Lamont-Doherty Earth Observatory, Columbia University, New York, NY 10964, USA 
wave-induced perturbations on both sides of the interface have been observed and accounted for as deviations from the classic rigid-boundary-layer dynamics. For example, one waveinduced effect in the water column is a result of wave breaking that transfers wave energy into the water column. The time scale of the energy transfer varies from nearly continuous events associated with microbreaking to more intermittent events associated with large-scale breaking and whitecaps. The small-scale breaking effectively transfers energy to the nearsurface currents contributing to the shear production of turbulent kinetic energy (TKE). The larger-scale breaking transfers energy to depths comparable to the significant wave height and leads to an enhancement of the TKE dissipation rate relative to the classic law-of-the-wall behaviour (e.g., Anis and Moum 1995; Terray et al. 1996; Drennan et al. 1996; Scully et al. 2016). This TKE injection due to wave breaking leads to enhanced mixing facilitating gas transfer (e.g., carbon dioxide $\left(\mathrm{CO}_{2}\right)$ and dimethyl sulfide (DMS)) between atmosphere and ocean (e.g., Brumer et al. 2017).

In the lower atmosphere above the wave-affected layer, Monin-Obukhov similarity theory (MOST) applies (e.g., Edson and Fairall 1998), but fails closer to the interface in the presence of wave-induced perturbations (e.g., Hare et al. 1997). Observations and theory have shown that the departure from MOST can be linked to the flux divergence of the wave-induced pressure transport term and the non-zero flux of energy into the growing wave field (Janssen 1999; Edson et al. 2007), which arises as a consequence of the wave-induced perturbations to the airflow. The non-zero energy flux across the air-sea interface results in a dissipation deficit compared to the law-of-the-wall prediction due to the reduction of energy that must be dissipated in the atmospheric surface layer (Sect. 2). This scenario is expected under growing seas (i.e. young seas), where there is active kinetic energy and momentum transfer from atmosphere to ocean. On the other hand, swell-driven perturbations on the airflow can also lead to departures from MOST (e.g., Grachev and Fairall 2001; Smedman et al. 2009), corresponding to fast waves propagating under weak wind forcing (i.e. mature seas) and leading to what has been called a wave-driven wind (e.g., Harris 1966; Högström et al. 2013). In both cases wave-induced perturbations for young and old seas dynamically coupled to the airflow have a significant impact on air-sea transfer dynamics.

Nonetheless, the dynamic coupling between ocean and atmosphere is expected to be finite in space, as wave perturbations on the airflow only protrude to a certain height in the atmosphere and depth in the ocean. Above and below this air-sea layer, the turbulent exchange becomes independent of the wave field, and converges to a law-of-the-wall type of behaviour (e.g., Lombardo and Gregg 1989; Zappa et al. 2012). How high into the atmosphere or how deep into the water column the wind and wave coupling extends is an ongoing area of research. The early wave-generation theory of Miles (1957) defined a critical-layer height $\left(z_{c}\right)$ above the surface below which flow is directly influenced by waves, where the following condition is satisfied: $U\left(z_{c}\right)=c$, where $U\left(z_{c}\right)$ is the mean wind speed at the critical height and $c$ is the wave phase speed in a monochromatic wave field. Wave-growth in Miles (1957) was explained by the wave-induced perturbations (i.e. pressure) on the airflow becoming resonant with the wave field directly at the critical-layer height. The theory was discredited by early experiments (i.e. Dobson 1971) and by numerical studies (e.g., Chalikov and Makin 1991; Belcher and Hunt 1993; Mastenbroek et al. 1996) due to its linearity and lack of turbulent Reynolds stresses in the airflow, suggesting that the theory was insufficient to account for modelled and observed wave-growth under all conditions. The numerical studies of Belcher and Hunt (1993) defined the inner region, as a wave-adjacent layer where the wave-induced perturbation of the Reynolds stresses leads to non-separated sheltering. Relative to these numerical efforts the Miles mechanism becomes relevant only when the inner region $\left(L_{i}\right)$ 
and the critical height $\left(z_{c}\right)$ are of the same order of magnitude, which occurs for intermediate wave scales $\left(15<c / u_{*}<25\right)$, where $u_{*}$ is the atmospheric friction velocity.

Nonetheless, recent fieldwork has suggested the validity of the Miles (1957) theory by identifying wave-induced perturbations on the airflow, which are in agreement with the critical-layer height $\left(z_{c}\right)$ framework (e.g., Hristov et al. 2003; Grare et al. 2013). Both of these field studies relied on spectral methods to identify and explore the wave-coherent perturbations on the airflow, suggesting that the Miles mechanism may be sufficiently accurate to model wave growth, particularly for the continuous spectrum of waves observed over the ocean. The definition of a critical layer, or the height of a wave boundary layer on the atmospheric side over a spectrum of waves observed over the ocean, is a relevant physical aspect of air-sea interaction and wind-driven wave dynamics. Ideally, direct measurements of the wave-induced momentum flux would be performed to quantify the behaviour of these flux components throughout the WBL and into the overlying surface layer as a function of waveand turbulence-related scaling parameters. Unfortunately, direct measurements of this flux and its behaviour across the marine boundary layer are extremely difficult to make. Estimates of the surface flux and flux divergence away from the surface require static pressure and waveperturbed velocities to be measured as close to the surface as possible. This complicates the instrument deployment due to the presence of the waves and analysis due to any motion of the measurement platform and sensors. At the same time separating the turbulent from purely wave-induced signal is hard to achieve (e.g., Rieder and Smith 1998; Hristov et al. 2003; Grare et al. 2013). The most direct measurements of the surface stress supported by waves involve atmospheric pressure observations from wave followers, towers or stabilized platforms and subsequent extrapolation from a given height down to the surface (e.g., Snyder et al. 1981; Hasselmann and Bösenberg 1991; Donelan et al. 2006). The extrapolated pressure measurements are then correlated with the wave slope to estimate the wave stress supported by the longer waves commonly referred to as form drag. However, this approach unavoidably misses the contribution of the shorter waves to the form drag due to the rapid decay of the wave-induced signature of these waves. Traditional phase averaging of the velocity field (e.g., Finnigan et al. 1984) has also been attempted (Wetzel 1996), but is difficult to implement unless the wave field has a very narrow spectral peak.

Our study attempts to define the height of the wave-affected boundary layer (WBL) within the marine surface layer under conditions where the interaction between wind and waves is assumed to be strong. The investigation takes advantage of a set of observations made in the open ocean during the Southern Ocean Gas Exchange Experiment (SO GasEx) between the months of March and April 2008. This dataset was used to explore a height-dependent function that models the decay of the wave-induced momentum away from the surface based on previous observational and modelling studies (e.g., Makin and Kudryavtsev 1999; Chalikov and Rainchik 2011). The height of the WBL is derived using one-dimensional energy and momentum balances between wind and waves. This approach leads to the definition of an effective wave scale (e.g., phase speed) as the largest wave actively coupled with the wind under the observed open ocean conditions. The paper is organized as follows: an overview of the theory and assumptions made in the momentum and energy balances is provided in Sect. 2. Section 3 shows the experimental set-up and describes the overall physical conditions during the field campaign. Section 4 shows the results of the one-dimensional model, where we focus on the decay rate of the wave-induced perturbations and the height of the WBL. In Sect. 5 we discuss the main results and explore the effective wave scale in the context of previous work (i.e. Terray et al. 1996). Finally, Sect. 6 summarizes our main conclusions. 


\section{Theoretical Background}

\subsection{Turbulent Kinetic Energy Budget}

We begin by introducing the classic velocity and pressure decomposition as the sum of a mean (denoted in brackets) and turbulent component (denoted with a prime) and a wave-induced perturbation (denoted with a tilde),

$$
\begin{gathered}
u_{i}=\langle u\rangle_{i}+\tilde{u}_{i}+u_{i}^{\prime}, \\
p=\langle p\rangle+\tilde{p}+p^{\prime},
\end{gathered}
$$

where subscript $i=1,2,3$ represents the along-wind, crosswind, and vertical velocity components that we denote by $u, v$, and $w$, respectively. In practice, the averaging is done over $20 \mathrm{~min}$, which is considered a suitable time period for flux calculations under open-ocean conditions. Using this decomposition we write the vertical TKE balance for steady-state neutral conditions above the air-sea interface as,

$$
-\frac{\partial U}{\partial z}\left[\left\langle u^{\prime} w^{\prime}\right\rangle+\langle\tilde{u} \tilde{w}\rangle\right]-\frac{\partial}{\partial z}\left[\frac{1}{\rho_{a}}\left\langle w^{\prime} p^{\prime}\right\rangle+\left\langle e^{\prime} w^{\prime}\right\rangle\right]-\frac{1}{\rho_{a}} \frac{\partial\langle\tilde{w} \tilde{p}\rangle}{\partial z}=\varepsilon,
$$

where the wind vector has been rotated into the mean along-wind direction and $z$ denotes the vertical spatial component. The first term on the left-hand side (1.h.s.) of Eq. 2 represents the shear production of TKE, where the total stress has a turbulent (i.e. $\left\langle u^{\prime} w^{\prime}\right\rangle$ ) and a wave-induced component (i.e. $\langle\tilde{u} \tilde{w}\rangle$ ). The wave-induced pressure fluctuation (i.e. $\tilde{p}$ ) leads to a vertical flux of kinetic energy by wave-induced motions (i.e. $\langle\tilde{w} \tilde{p}\rangle)$. Note that in Eq. 2 we have neglected the wave-induced vertical transport of TKE (i.e. $\langle\tilde{w} \tilde{e}\rangle$ ). Theoretical considerations render the vertical transport of TKE by wave-induced perturbations negligible relative to the pressure perturbations (i.e. $\langle\tilde{w} \tilde{p}\rangle$ ) (e.g., Janssen 1999). The second term on the 1.h.s. of Eq. 2 is a turbulent transport term (i.e. $\left[\left\langle w^{\prime} p^{\prime}\right\rangle+\left\langle e w^{\prime}\right\rangle\right]$ ) and the third term, arising from wave-induced pressure perturbations, corresponds to the wave-induced energy-flux divergence active in the WBL. Finally, the right-hand side (r.h.s.) corresponds to the TKE dissipation rate ( $\varepsilon$ ). Within the WBL the rigid-boundary-layer scaling and MOST no longer apply (Hare et al. 1997; Janssen 1999). Also, oscillations of the wave-induced momentum and pressure perturbations have been observed (i.e. Wetzel 1996; Hare et al. 1997) and modelled (i.e. Mastenbroek et al. 1996), but the vertical structure remains elusive. Here, the vertical momentum flux is supported by turbulence and waves, but the total momentum flux above the wave field remains independent of height (within 10\%). The transport terms are usually neglected in Eq. 2, as they have been shown to cancel each other in the atmospheric surface layer (e.g., Wyngaard and Coté 1971; McBean and Elliott 1975). Therefore Eq. 2 reduces to,

$$
-\frac{\partial U}{\partial z}\left[\left\langle u^{\prime} w^{\prime}\right\rangle+\langle\tilde{u} \tilde{w}\rangle\right]-\frac{1}{\rho_{a}} \frac{\partial\langle\tilde{w} \tilde{p}\rangle}{\partial z}-\varepsilon=0 .
$$

Equation 3 is similar to the total energy balance in Hara and Belcher (2004) and states a balance between TKE production and dissipation and the wave-driven energy-flux divergence. Previous WBL modelling efforts have assumed a local balance between turbulent TKE production and dissipation (e.g., Burgers and Makin 1993; Chalikov and Belevich 1993; Chalikov 1995; Makin and Kudryavtsev 1999). Here, we assume that within the WBL the locally reduced turbulent stress leads to a reduced TKE shear production (Sect. 2.2) and is locally balanced by a reduced TKE dissipation rate (i.e. local TKE dissipation deficit rela- 
tive to the rigid-boundary-layer scaling) and propose a balance within the WBL between the wave-driven terms in Eq. 3, viz.

$$
-\frac{\partial U}{\partial z}\langle\tilde{u} \tilde{w}\rangle-\frac{1}{\rho_{a}} \frac{\partial\langle\tilde{w} \tilde{p}\rangle}{\partial z}=0,
$$

where $U$ is the mean wind speed and $\rho_{a}$ is the air density. Equation 4 states that all kinetic energy being extracted from the mean flow (first term on the 1.h.s.) supports wave growth by means of the kinetic-energy-flux divergence (second term on the 1.h.s.) arising from waveinduced perturbations. Integration over height gives,

$$
-\rho_{a} \int_{z} \frac{\partial U}{\partial z}\langle\tilde{u} \tilde{w}\rangle_{o} \mathrm{~d} z=\langle\tilde{w} \tilde{p}\rangle_{z}-\langle\tilde{w} \tilde{p}\rangle_{o},
$$

where for $z$ well above the WBL the first term on the r.h.s. goes to zero. The 1.h.s. of Eq. 5 corresponds to the rate of work done by the wave-induced momentum flux on the mean wind shear (i.e. Lighthill 1962). The second term on the r.h.s. is the energy flux into the wave field (e.g., Hara and Belcher 2004). Therefore, integration of the 1.h.s. of Eq. 5 over height provides an estimate of the atmospheric energy input to the wave field (i.e., an energy extraction mechanism). More commonly (e.g., Terray et al. 1996; Donelan et al. 2006), the energy flux is estimated from surface wave spectra as,

$$
E_{a w}=\int_{\omega} \omega \beta(\omega) F(\omega) \mathrm{d} \omega,
$$

where $E_{a w}$ is the wind energy going into the wave field, $F(\omega)$ is the one-dimensional wave spectrum, $\beta(\omega)$ is a wave-growth parameter, $\omega$ is the angular frequency $(\omega=2 \pi f), g$ is the acceleration due to gravity and $\rho_{w}$ is the water density. These two estimates of the energy flux are investigated together below.

\subsection{Momentum Flux Across the Wave Boundary Layer}

The total momentum flux $(\tau)$ at the surface layer is assumed to be independent of height, where a small momentum-flux divergence, i.e. $\partial \tau(z) / \partial z \approx 0$ is satisfied within the lower marine boundary layer. Then we write the total momentum flux within the surface layer in terms of the atmospheric friction velocity $\left(u_{*}\right)$ and decompose it into turbulent, wave-induced and viscous stresses,

$$
\tau=\rho_{a} u_{*}^{2}=-\rho_{a}\left[\left\langle u^{\prime} w^{\prime}\right\rangle+\langle\tilde{u} \tilde{w}\rangle\right]+\tau_{v},
$$

where $-\rho_{a}\left\langle u^{\prime} w^{\prime}\right\rangle$ is the turbulent stress component, the negative sign indicating a momentum transfer from the atmosphere to the ocean. The wave-induced stress $-\rho_{a}\langle\tilde{u} \tilde{w}\rangle$ is also negative under growing seas, but can revert sign under swell-dominated conditions in the presence of weak wind forcing and reverse the transfer of momentum from ocean to atmosphere (e.g., Grachev and Fairall 2001; Högström et al. 2009). Finally, the viscous stress, $\tau_{v}$, is added to the turbulent and wave-induced components of the stress and physically accounts for tangential frictional forces at the air-sea interface. The turbulent component of the stress is expected to vanish at the air-sea interface and the total momentum flux is composed of the wave-induced and viscous stresses given by

$$
\tau=-\rho_{a}\langle\tilde{u} \tilde{w}\rangle+\tau_{v} .
$$

The viscous stress can be a significant component of the surface stress, particularly under light wind conditions, but rapidly becomes negligible a few tens of metres above the surface. 
As a result, the turbulent and wave-induced components must exhibit a strong functionality with height for the total stress to remain approximately constant (i.e. height independent) in the surface layer. For example, as the wave-induced flux decays with height, the turbulent component increases until the total flux is supported by atmospheric turbulence above the WBL.

The viscous stress $\left(\tau_{v}\right)$ is given by

$$
\tau_{v}=\mu \frac{d u_{v}}{\mathrm{~d} z}
$$

where $u_{v}$ is the velocity inside the purely viscous region and $\mu$ is the dynamic viscosity in air. The velocity profile is assumed to be linear in the viscous sublayer such that by matching the normalized wind speeds at $z=\delta_{v}$, where $\delta_{v}$ is the depth of the viscous layer, the viscous stress can be written as (Kudryavtsev and Makin 2001),

$$
\tau_{v}=(\kappa d)^{-1}\left(\delta / z_{0}\right) u_{*}^{2},
$$

where $z_{0}$ is the aerodynamic roughness length, $\kappa$ is the von Karman constant and the depth of the viscous sublayer is given by

$$
\delta_{v}=d \frac{v}{u_{*}},
$$

where $v$ is the kinematic viscosity and $d$ is a numerical constant. The smooth flow assumption requires that $d=11.7$ although lower values of $d$ are also found in the literature: $d \approx 5$ (Monin and Yaglom 1975). However, the larger value provides agreement with momentum fluxes measured at low wind speeds (Edson et al. 2007). Once the viscous stress is defined, the momentum balance at the interface can be stated as,

$$
\rho_{a}\langle\tilde{u} \tilde{w}\rangle_{o}=\rho_{a} u_{*}^{2}-\tau_{v},
$$

where the wave-induced momentum flux at the interface $\left(\rho_{a}\left\langle\tilde{u} \tilde{w}_{o}\right\rangle\right)$ is given in terms of the wave spectrum $F(\omega)$,

$$
\rho_{a}\langle\tilde{u} \tilde{w}\rangle_{o}=M_{w}=\int_{\omega} M(\omega) \mathrm{d} \omega=\rho_{w} g \int_{\omega} \frac{\beta(\omega)}{c(\omega)} F(\omega) \mathrm{d} \omega,
$$

where we have used $M(\omega)=E(\omega) / c(\omega)$ relating momentum to energy at a given frequency. This corresponds to the stress directly supported by the wave field, where the wave-growth parameter, $\beta(\omega)$, is defined as the fractional spectral energy increase due to wind input.

\subsection{Wave-Induced Energy and Momentum Flux Across the WBL}

We introduce a simple height dependence, which follows from potential flow theory, where the wave-induced perturbations decay exponentially with height. Previous work has also relied on the exponential decay to describe the vertical behaviour of the wave-induced perturbations in the lower atmosphere (e.g., Högström et al. 2009; Wu et al. 2017). The difficult task is then defining the decay coefficient in the exponential function. For example, based on large-eddy simulation (LES) results, Högstrom et al. (2009) used a dimensionless decay coefficient of 1.9 to model the decay of the wave-induced stress (form drag) under swelldominated conditions. Also, a compilation of different datasets by Högström et al. (2015) explored the exponential decay of the swell-driven signature on the $u-w$ cospectra. The spectral measurements at different heights allowed Högström et al. (2015) to estimate a decay coefficient in the 1-2.1 range. Finally, Wu et al. (2017) also relying on LES (e.g., Högström 
et al. 2009) explored values of the decay coefficient for different wave-induced perturbations in the lower atmosphere. The present work assumes the following height dependence on the wave-induced momentum flux throughout the WBL,

$$
\langle\tilde{u} \tilde{w}\rangle_{z}=\langle\tilde{u} \tilde{w}\rangle_{o} \exp (-A z),
$$

where the wave-induced momentum at the interface can be estimated from either (12) if the difference between the total and the viscous stress can be estimated, or (13) using previously published wave-growth parameters and sea-surface wave spectra.

We define the decay rate as $A=\alpha k$, where $\alpha$ is the commonly used dimensionless decay rate (e.g., Wu et al. 2017) and we set $k$ as the wavenumber of the largest wind-driven wave under active coupling. This wavenumber scale remains initially undefined and is to be determined from the one-dimensional energy balance (Sect. 2.1); defined this way, the dimensional decay rate $A$ has units of $\mathrm{m}^{-1}$ and is used in Eq. 14 to account for the decay of the wave-induced stress away from the interface. Replacing Eq. 14 into the 1.h.s. of Eq. 5 provides a form of the integrated energy input throughout the WBL from the atmosphere into the waves is given by

$$
\langle\tilde{w} \tilde{p}\rangle_{o}=-\rho_{a} \int_{z_{o}}^{Z} \frac{\partial U}{\partial z}\langle\tilde{u} \tilde{w}\rangle_{o} \exp (-A z) \mathrm{d} z,
$$

where the lower integration limit is defined as $z=z_{0}$ and the upper limit as $z=Z$. The limits are set to integrate above the viscous layer and high enough into the WBL to render wave-induced perturbations negligible. The integration of Eq. 15 within the WBL requires modification of the wind shear to account for the expected wave-induced perturbations in the flow. We begin by defining a local friction velocity that attempts to account for the height dependence of the turbulent wind stress as (e.g., Makin et al. 1995)

$$
u_{*}^{l}(z)=u_{*} \sqrt{\left(1-\alpha_{c} e^{-A z}\right)},
$$

where $u_{*}^{l}(z)$ is the local friction velocity for the wave-affected region, $\alpha_{c}$ is defined as the ratio of the wave-induced to total stress evaluated at the interface (e.g., Janssen 1989; Kudryavtsev and Makin 2001). The velocity profile inside the WBL is then parametrized in terms of the local friction velocity as

$$
\frac{\partial U^{l}}{\partial z}=\frac{\left(u_{*}^{l}(z)\right)^{2}}{K_{m}},
$$

where $U^{l}$ is the local mean wind speed inside the WBL and $K_{m}$ is the eddy viscosity. A simple $K_{m}$ parametrization based on the mixing length approach leads to,

$$
\frac{\partial U^{l}}{\partial z}=\frac{u_{*}^{l}(z)}{\kappa z}
$$

where $u_{*}^{l}(z)$ follows from Eq. 16. Finally, we have from Eq. 14

$$
\langle\tilde{w} \tilde{p}\rangle_{o}=-\rho_{a}\langle\tilde{u} \tilde{w}\rangle_{o} \int_{z_{o}}^{Z} \frac{\partial U^{l}}{\partial z} \exp (-A z) \mathrm{d} z .
$$

The energy extraction from the mean flow through the WBL given by Eq. 19 should equal the observed spectral wind energy of the wave field given by Eq. 6. Then, this balance between the extraction of energy from the mean flow by the wave-induced stress and the wind inputted energy to the wave field was stated as

$$
E_{a w}=g \rho_{w} \int_{\omega} \omega \beta(\omega) F(\omega) \mathrm{d} \omega=\langle\tilde{w} \tilde{p}\rangle_{o}=\rho_{a}\langle\tilde{u} \tilde{w}\rangle_{o} \int_{z_{o}}^{Z} \frac{\partial U^{l}}{\partial z} \exp (-A z) \mathrm{d} z
$$




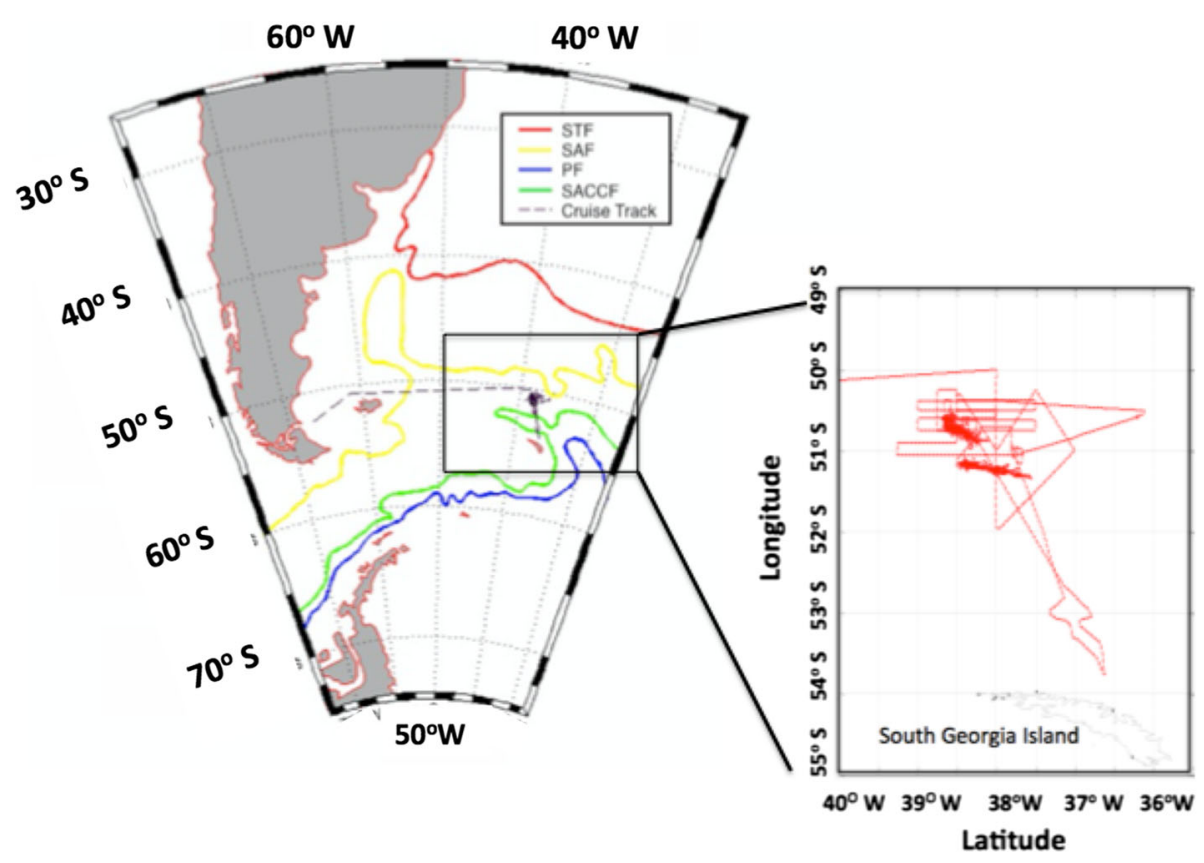

Fig. 1 Cruise Location and Cruise Tracks (insert) during the Southern Ocean Gas Exchange Experiment. The field campaign took place between March and April 2008 with departure from Punta Arenas, Chile. The island in the insert corresponds to South Georgia; Ocean Fronts are colour-coded: the Subtropical Front (STF), the Subantarctic Front (SAF), the Polar Front (PF), the Southern Antarctic Circumpolar Current Front (SACCF), and the Southern Boundary of the Antarctic Circumpolar Current (SBDY)

Estimates of the energy flux can be obtained using measured wave spectra and one of several commonly used wave-growth parameters (e.g., Snyder et al. 1981; Plant 1982; Donelan and Pierson 1987; Janssen 1991). The r.h.s. can be can be solved iteratively and modified via the decay rate $A$ in order to minimize the difference $\left(\epsilon_{e r r}\right)$,

$$
\epsilon_{\text {err }}=\min \left\{E_{a w}(A)-\langle\tilde{w} \tilde{p}\rangle_{o}\right\}
$$

Different wave-growth parametrizations can be evaluated to determine the combination of $\beta$ and $A$ that minimizes $\in_{e r r}$.

\section{Field Experiment and Observations}

The SO GasEx was designed to investigate the processes governing gas exchange at high wind speed by implementing the dual tracer (Ho et al. 2011) and the direct covariance technique (Edson et al. 2011). The experiment took place in the southern portion of the Atlantic Ocean (Fig. 1) on board of the NOAA Ship Ronald H. Brown during the months of March and April 2008, where a sufficiently large $\mathrm{CO}_{2}$ concentration $(C)$ difference between atmosphere and ocean was expected $(\Delta C>50 \mu \mathrm{atm})$ in order to implement the direct covariance method.

Atmospheric measurements were made using a meteorological package mounted on the jack-staff of the ship. This package consisted of three Gill R-3 sonic anemometers (Gill Instruments, Hampshire, UK) for fast response velocity and virtual temperature measure- 


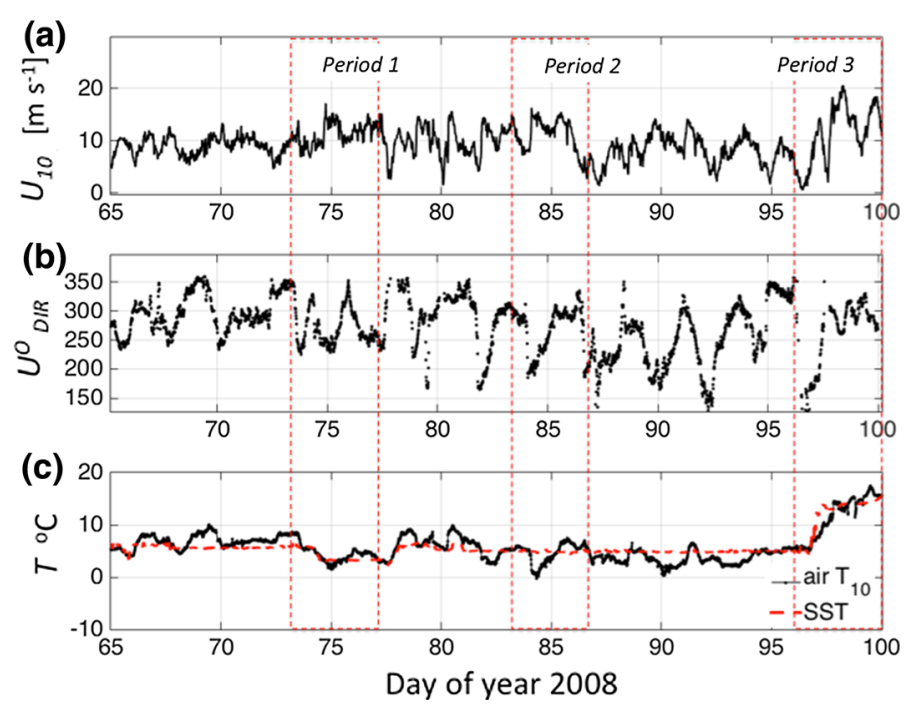

Fig. 2 Time series (day of year 2008) of wind speed at a 10-m reference height $\left(U_{10}\right)$, wind direction $\left(U^{o}\right)$, sea and air temperature $(T)$. a Wind speed at 10-m height. b Wind direction. c Air temperature at 10-m height (solid black line) and sea-surface temperature (SST, dashed red line). All measurements collected on board of the NOAA R.V Ronald Brown. The red rectangles show the periods later analyzed

ments, three open path LI-COR 7500 (LI-COR, Lincoln, Nebraska, USA) for fast response atmospheric water vapour and $\mathrm{CO}_{2}$ concentration measurements, and two Vaisala PTU200 (Vaisala, Helsinki, Finland) sensors to measure pressure, temperature and humidity.

The experiment was carried out with consistently moderate to high wind speeds $\left(5 \leq U_{10}\right.$ $\left.\leq 18 \mathrm{~m} \mathrm{~s}^{-1}\right)$, with a severe wind event $\left(U_{10}>18 \mathrm{~m} \mathrm{~s}^{-1}\right)$ encountered at the end of the field campaign (Fig. 2). The atmospheric measurements were complemented with an array of wave-field measurements.

The sonic anemometers with a sampling frequency of $20 \mathrm{~Hz}$ were paired with inertial measurement units (Systron-Donner Inertial, Concord, California, USA) to remove platform motion before calculation of the fluxes (Edson et al. 1998). The pre-processing scheme also included rotation and alignment of the sonic anemometers with the ship's right-hand coordinate system. Furthermore, directional considerations were taken into account in order to minimize flow distortion. Turbulent fluxes were calculated from 20-min bin averages from 1-h data segments, and measurements were used to estimate the mean neutral wind speed at a reference height of $10 \mathrm{~m}$, the corresponding atmospheric friction velocity and to estimate turbulent fluxes of heat and momentum. The turbulent vertical momentum flux computed at approximately $z=18 \mathrm{~m}$ is shown in Fig. 3 with bulk estimates of the flux using the COARE 3.5 algorithm (Edson et al. 2013).

Wave statistics such as significant wave height (Fig. 4) and period were provided by an Xband radar (WaMoS) (OceanWaveS GmbH, Lueneburg, Germany), a laser altimeter RIEGL LD90 (RIEGL Laser Measurements Systems GmbH, Horn, Austria) and a microwave sensor (TSK) (Tsurumi-Seiki Co. Ltd, Kanagawa, Japan). The inertial measurement units were also used to calculate the heave of the ship at its centre-of-mass (Ship-CM). The combination of the WaMoS data (low frequency) with the RIEGL data (high frequency) provided wave spectra over a frequency band between 0.035 and $1.2 \mathrm{~Hz}$ with a high-frequency slope of $f^{-4}$ and good signal-to-noise ratio (e.g., Cifuentes-Lorenzen et al. 2013). 


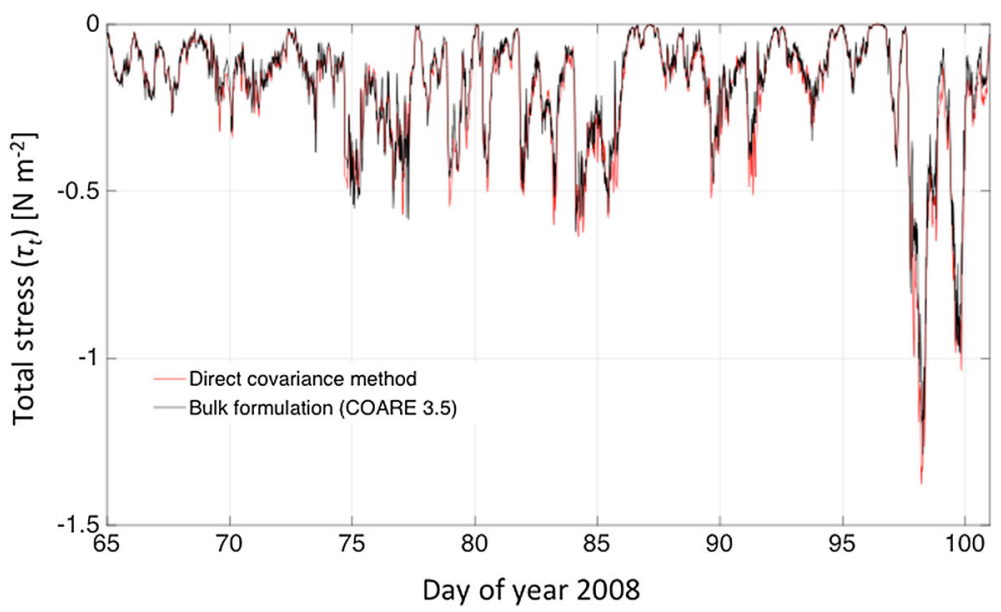

Fig. 3 Time series of the total momentum flux from direct covariance method shown in solid red line and the bulk formulation COARE shown in solid black. All measurements collected on board of the NOAA R.V Ronald Brown. During the SO GasEx campaign, the direct covariance estimates of the momentum transfer were uniformly about $10 \%$ greater than estimates from the COARE 3.5 algorithm (Edson et al. 2011)

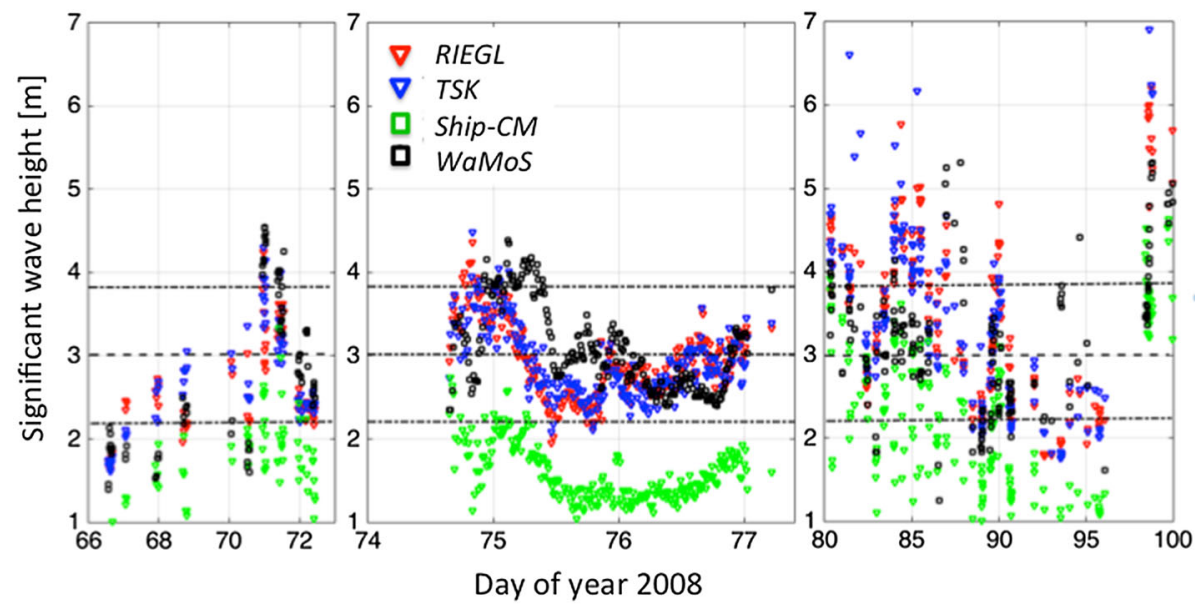

Fig. 4 Significant wave height from the wave instrumentation deployed during the SO GasEx. The RIEGL laser altimeter mounted on the jack-staff, the TSK microwave sensor mounted at the bow of the ship. The WaMoS system an X-band radar on the flying bridge and Ship-CM corresponds to the low frequency signal at the ship's centre-of-mass from the inertial measurement units. Here we present a comparison of the measurements and an example of the overall wave conditions during the selected periods for our study (Cifuentes-Lorenzen et al. 2013)

The wave age, defined as $\left\langle c_{p} / u_{*}\right\rangle$, was used to characterize the sea state as young (developing), mature (developed) or old (decaying). During the field campaign we observed, on average, mature or fully developed seas (e.g., Drennan et al. 2003; Edson et al. 2013) with an average wave age of $\left\langle c_{p} / u_{*}\right\rangle=65$. From the entire record we selected younger periods (Sect. 4) that also satisfied directional constraints and maximum ship ground speed, which was limited to $3 \mathrm{~m} \mathrm{~s}^{-1}$. Significant wave heights averaged $3.2 \mathrm{~m}$ throughout the experiment, reaching up to $7 \mathrm{~m}$ under severe conditions (Fig. 4). 
Spectrally, the wave field exhibited a weak bimodal spectral distribution, with wind-wave peaks that were usually overwhelmed by the swell component of the wave field. This can be explained by looking at the general circulation over the Southern Ocean, which predicts, on average, a persistent westerly wind between the sub-tropical anticyclone and the sub-polar low-pressure systems. This prevalent westerly flow drives the Antarctic Circumpolar Current through the Drake Passage connecting the Pacific and the Atlantic Oceans. The westerly winds exert a total stress ranging between $0.12-1.35 \mathrm{~N} \mathrm{~m}^{-2}$ with a mean of $0.2 \mathrm{~N} \mathrm{~m}^{-2}$ with an almost constant eastward direction. This region of the ocean presents no fetch limitations, allowing the wind, waves, and currents to evolve and develop without spatial or temporal constraints.

It is this relatively constant wind direction that forces a wave field with a weakly bimodal spectral distribution. The dominant wave scales show a frequency range of $0.08<f<0.12 \mathrm{~Hz}$, which we associate with the background swell component of the wave field. During storm passages and strong forcing, the spectra eventually develops a more clearly defined secondary peak in the frequency range $0.13<f<0.2 \mathrm{~Hz}$. The relative directional homogeneity of the wind forcing leads this secondary peak to develop in the same direction $\left( \pm 40^{\circ}\right)$ as exhibited by the swell component, with locally wind-driven waves riding on top of the swell component.

\section{Results}

\subsection{Overall Conditions}

The wave spectrum is defined by complementing the WaMoS (low-frequency) and the RIEGL (high-frequency) measurements, which yielded a frequency spectrum in the range $0.035 \leq f$ $\leq 1.2 \mathrm{~Hz}$. The measured frequency spectra were then extended to $2 \mathrm{~Hz}$ following a $f^{-4}$ $\mathrm{Hz}$ tail roll-off, allowing the resolution of wavelengths $<1 \mathrm{~m}$ (i.e. down to $0.7 \mathrm{~m}$ ) and with phase speeds of $1 \mathrm{~m} \mathrm{~s}^{-1}$. We based our analysis on three periods of interest, which allowed a comparison between moderate to high wind forcing in an effort to minimize the presence of old seas in our analysis. During these periods, favourable conditions were observed in terms of co-alignment between the relative direction of the wind, waves, and ship's heading.

Period 1 was selected between day 74.5-77 (i.e. 1400 UTC on 14 March 2008 to 0000 UTC on 17 March 2008) with a mean wind speed of $12.2 \mathrm{~m} \mathrm{~s}^{-1}$ and average significant wave height of $3 \mathrm{~m}$. The average wave age, $\left\langle c_{p} / u_{*}\right\rangle$, during this period was $30.5 \pm 4.5$, indicating the presence of developed to mature seas, with this period providing the greatest variability in the wave field as shown in Fig. 5. Earlier severe seas gradually decayed over time (Fig. 5; Period 1), with significant wave heights initially reaching $4 \mathrm{~m}$ and then decaying to $2.5 \mathrm{~m}$. This is reflected in the spectral estimates shown in Fig. 5 (Period 1), where the wave energy decreses by approximately $50 \%$ throughout the record. The decay of spectral energy is also accompanied by a shift in the peak frequencies as the dominant waves become shorter.

The second period of interest (period 2) was selected between day 83-86 (i.e. 0000 UTC on 23 March 2008 to 0000 UTC on 25 March 2008) with an average wind speed of $12.8 \mathrm{~m} \mathrm{~s}^{-1}$ and a mean significant wave height of $3.4 \mathrm{~m}$. Period 2 was on average more developed, with $\left\langle c_{p} / u_{*}\right\rangle=37.4 \pm 10.8$, and the variability in the wave field was lower with an almost constant phase speed of $15 \mathrm{~m} \mathrm{~s}^{-1}$. Most of the variability that was observed in the wave age was due to changing local wind speeds between 9.5 and $15.3 \mathrm{~m} \mathrm{~s}^{-1}$. Mean significant wave heights were $3.4 \mathrm{~m}$ with a maximum of $5.1 \mathrm{~m}$. This maximum significant wave height event can be 

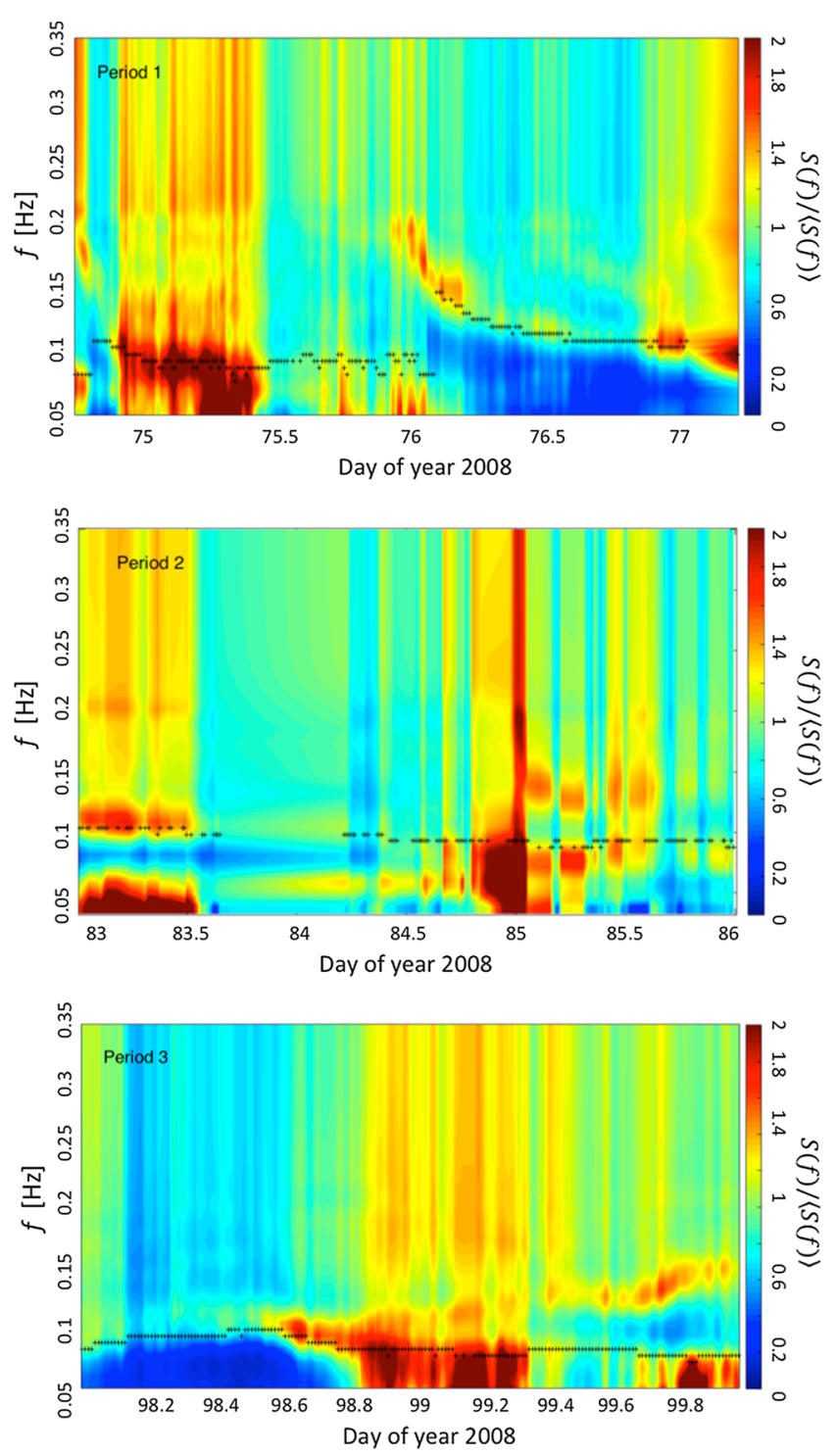

Fig. 5 Normalized spectrogram from WaMoS during period 1 (top panel), period 2 (mid panel) and period 3 (bottom panel). Normalization renders the spectra dimensionless. All periods show different wave-field conditions despite similar average wave ages. Top panel (period 1): early stronger forcing leads to high-energy seas that decay over the period. This period shows the widest range of peak phase speeds (and peak frequencies shown in black +). During period 1 the ship's speed over ground was $\leq 1 \mathrm{~m} \mathrm{~s}^{-1}$ i.e. station keeping with the bow of the ship oriented into the wind minimizing flow distortion together with minimum motion contamination. Middle panel (period 2) shows a relatively steady wave field where the changes in wave age were driven by wind forcing conditions. The spectral energy enhancement during day of year 85 is associated to non-local swell propagating by the experiment site. For period 2 we allowed a speed over ground $\leq 3 \mathrm{~m} \mathrm{~s}^{-1}$ in order to include more data into the analysis. Bottom panel (period 3) develops throughout with a later spectral shift to higher frequencies under strong winds $\left(U_{10}>18 \mathrm{~m} \mathrm{~s}^{-1}\right)$ period 3 ship's speed over ground is below $3 \mathrm{~m} \mathrm{~s}^{-1}$, with most observations $\leq 2 \mathrm{~m} \mathrm{~s}^{-1}$. During this period the ship was also on station with the bow into the wind. All spectrograms present the frequency range $0.05-0.35 \mathrm{~Hz}$ from WaMoS with no added high-frequency complement and no added spectral tail 
seen in Fig. 5 (period 2) with an increase in spectral energy (day of year 85). This event was associated with non-local high energy swell propagating through the region.

Finally, period 3 was selected between day 98-100 (i.e. 0000 UTC on 7 April 2008 to 0000 UTC on 9 April 2008) with an average wind speed of $14.8 \mathrm{~m} \mathrm{~s}^{-1}$ and a mean significant wave height of $5 \mathrm{~m}$. Although period 3 also exhibited mature seas, with $\left\langle c_{p} / u_{*}\right\rangle=35.5 \pm$ 12.2 , the dynamic range for the wave age was larger. For example, during the first half of day 98 the wave age was $\left\langle c_{p} / u_{*}\right\rangle=25.3 \pm 4.2$, indicative of growing seas (Figs. 3 and 5) as a low pressure system propagated through the region with wind speeds exceeding $20 \mathrm{~m} \mathrm{~s}^{-1}$, leading to large momentum fluxes (Fig. 4). As the wave field developed the wind speeds diminished for a time before increasing toward the end of the period (day of year >99.3) driving locally-generated wind-waves over the larger swells. This can be seen in Fig. 5 in the shift of the peak period to higher frequencies, leading to shorter waves.

\subsection{Momentum Balance}

The momentum at the interface during all periods under consideration followed from Eq. 6 where the contribution of the viscous stress reached a maximum $5 \%$ of the total stress under fully rough flow. Furthermore, we constrained the data to allow wind and wave observations only when the ship's speed over ground was less than $3 \mathrm{~m} \mathrm{~s}^{-1}$ and for wind and wave directions aligned within $30^{\circ}$. The momentum closure at the interface was constrained for a wave age in the range $15 \leq c_{p} / u_{*} \leq 35$.

We compared the wave-induced momentum-flux estimates from our atmospheric measurements using Eq. 12 versus the estimates using our wave-spectral measurements with Eq. 13 using three different wave-growth parameters as described by Plant (1982), Janssen (1991) and Snyder et al. (1981). These three parametrizations were evaluated using the integrated value of the energy flux with no detailed attention given to the spectral contribution over a particular frequency band. Spectral estimates with different wave-growth parameters $\left(X_{i}\right)$, were compared to observations, $x_{i}$, and the performance was evaluated based on the root-mean-square (r.m.s.) error,

$$
\epsilon_{\mathrm{rms}}=\left[\left\langle(X-x)^{2}\right\rangle\right]^{1 / 2},
$$

and the index of agreement, $d$, which is a measure of the model skill (parametrization in this case), defined by Willmott et al. (1985) as

$$
d=1-\left[\sum_{i=1}^{N} \frac{\left(X_{i}-x_{i}\right)^{2}}{\sum_{i=1}^{N}\left(\left|X_{i}-\langle x\rangle\right|+\left|x_{i}-\langle x\rangle\right|\right)^{2}}\right],
$$

where the brackets denote temporal averages. The index of agreement ranges between zero (i.e. no agreement) and 1 (i.e. perfect agreement).

During all three periods under consideration the Snyder et al. (1981) parametrization provided the highest indices of agreement $(d)$ with values of $0.93,0.76$ and 0.92 for periods 1,2 and 3 respectively. This parametrization also exhibited the lowest r.m.s. error of 0.049 , 0.094 and $0.098 \mathrm{~N} \mathrm{~m}^{-2}$ for periods 1,2 and 3 respectively. The parametrization of Janssen (1991) had the tendency to overestimate the spectral input, particularly at a stronger forcing and yielded lower indices of agreement with values of $0.57,0.48$ and 0.34 for periods 1,2 and 3 respectively. The r.m.s. error estimates were $0.23,0.26$ and $1.25 \mathrm{~N} \mathrm{~m}^{-2}$ for periods 1 , 2 and 3 respectively.

The Plant (1982) parametrization exhibited a heavy weighting of the dominant frequency portion of the spectra, which we hypothesize is the reason behind the marked differences 


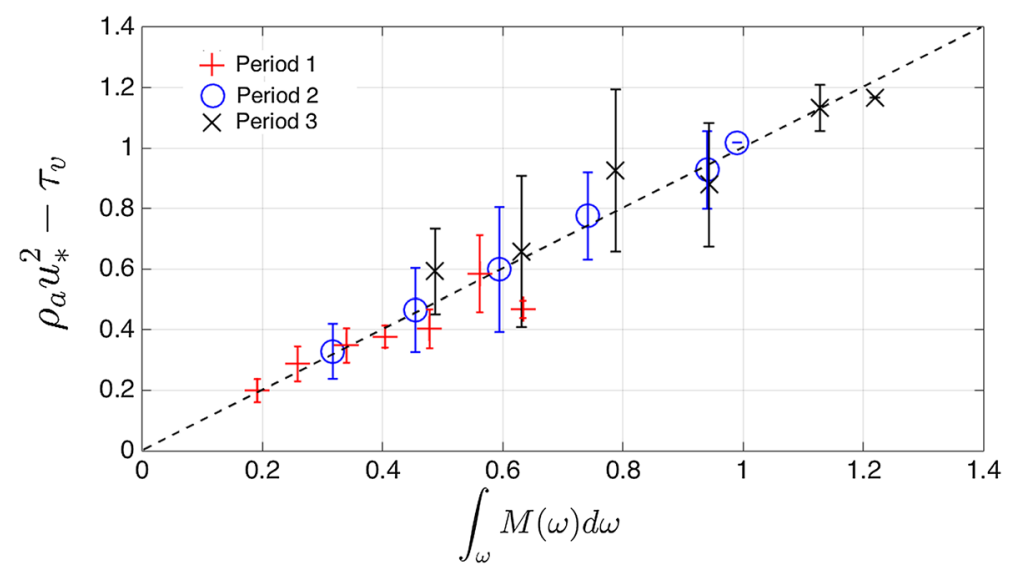

Fig. 6 Bin-averaged momentum balance for all periods under consideration based on the Snyder et al. (1981) wave-growth parametrization. The estimates reported here where further constrained for a wave age: $15 \leq$ $c_{p} / u_{*} \leq 35$. The error bars account for one standard deviation. Period 1: $d=0.93, \epsilon_{\mathrm{rms}}=0.049 \mathrm{~N} \mathrm{~m}^{-\overline{2}}$; period 2: $d=0.76, \epsilon_{\mathrm{rms}}=0.094 \mathrm{~N} \mathrm{~m}^{-2}$; period 3: $d=0.92 \epsilon_{\mathrm{rms}}=0.098 \mathrm{~N} \mathrm{~m}^{-2}$

compared to other parametrizations, with an overall overestimation of the growth. The index of agreement was estimated as $0.25,0.23$ and 0.17 for periods 1,2 and 3 respectively, and. the r.m.s. error is on average $>1 \mathrm{~N} \mathrm{~m}^{-2}$ (i.e. $\left\langle\epsilon_{\mathrm{rms}}\right\rangle>1 \mathrm{~N} \mathrm{~m}^{-2}$ ) for the conditions here presented.

Figure 6 shows the bin-averaged comparison of momentum flux for the wave-age range: $15 \leq c_{p} / u_{*} \leq 35$ based on the Snyder et al. (1981) wave-growth parametrization with good agreement extending out to $1.2 \mathrm{~N} \mathrm{~m}^{-2}$. The best momentum closure at the interface based on the observations here presented was achieved using the Snyder et al. (1981) wavegrowth parametrization, and so all estimates of energy (Sect. 4.3) have been made using this parametrization.

\subsection{Energy Balance Across the Wave Boundary Layer}

Under the set of assumptions introduced in Sect. 2.1, the energy extracted from the WBL is found by minimizing the difference between the two flux estimates given by Eq. 20 through adjustment of the decay rate $A$ to minimize $\epsilon_{e r r}$. Small values of $A$ lead to a slower decay with height, which implies that longer waves are coupled with the wind forcing. Tables 1 , 2 and 3 show the results of minimizing $\epsilon_{e r r}$ under different wave ages, where we used the atmospheric friction velocity as the velocity scale (i.e. $c_{p} / u_{*}$ ) where young seas are expected for $c_{p} / u_{*}<25$, mature sea are expected for: $25<c_{p} / u_{*}<40$, and situations with $c_{p} / u_{*}>40$, are considered old or decaying seas (i.e. swell).

These Tables also include the fractional error in the estimate and the number of data points used in the estimate, where the fractional error as a percentage $R$ is defined as

$$
<R>=100 \epsilon_{\text {err }} / E_{\text {aw }}
$$

where the spectral estimate is used as our reference measurement. For example, for the bin $15<c_{p} / u_{*}<25$, the average $\left\langle\tilde{w} \tilde{p}_{o}\right\rangle$ from Eq. 19 with $A=0.5$ was calculated to be 1.5 $\pm 0.4 \mathrm{~W} \mathrm{~m}^{-2}$ and the spectral estimate from Eq. 6 was estimated to be $1.4 \pm 0.5 \mathrm{~W} \mathrm{~m}^{-2}$ leading to the reported error in Table 1 . The same procedure was repeated for all error 
Table 1 Estimates of the average decay rate $A\left(\mathrm{~m}^{-1}\right)$ and the error associated with the estimate at different wave ages (i.e. $\left.c_{p} / u_{*}\right)$ for day of year $74.5-77($ period 1$)$

\begin{tabular}{lllllll}
\hline$c_{p} / u_{*}$ & $\begin{array}{l}>45 \\
(n=31)\end{array}$ & $\begin{array}{l}40-45 \\
(n=19)\end{array}$ & $\begin{array}{l}35-40 \\
(n=18)\end{array}$ & $\begin{array}{l}25-35 \\
(n=107)\end{array}$ & $\begin{array}{l}15-25 \\
(n=46)\end{array}$ & $\begin{array}{l}10-20 \\
(n=3)\end{array}$ \\
\hline$A\left[\mathrm{~m}^{-1}\right]$ & $>50$ & $>50$ & 25 & 1.0 & 0.5 & 1.0 \\
$<R>(\%)$ & $>50$ & $>35$ & 7 & 2 & 6 & 10 \\
\hline
\end{tabular}

Table 2 Estimates of the average decay rate $A\left(\mathrm{~m}^{-1)}\right.$ and the error associated with the estimate at different wave ages (i.e. $c_{p} / u_{*}$ ) for day of year $83-85($ period 2$)$

\begin{tabular}{|c|c|c|c|c|c|c|}
\hline$c_{p} / u_{*}$ & $\begin{array}{l}>45 \\
(n=20)\end{array}$ & $\begin{array}{l}40-45 \\
(n=20)\end{array}$ & $\begin{array}{l}35-40 \\
(n=21)\end{array}$ & $\begin{array}{l}25-35 \\
(n=85)\end{array}$ & $\begin{array}{l}15-25 \\
(n=44)\end{array}$ & $\begin{array}{l}10-20 \\
(n=3)\end{array}$ \\
\hline$A\left[\mathrm{~m}^{-1}\right]$ & $>50$ & 50 & 20 & 1.0 & 1.0 & 0.5 \\
\hline$<R>(\%)$ & $>65$ & 32 & 5 & $<1$ & $<1$ & 6 \\
\hline
\end{tabular}

Table 3 Estimates of the average decay rate $A\left(\mathrm{~m}^{-1}\right)$ and the error associated with the estimate at different wave ages (i.e. $\left.c_{p} / u_{*}\right)$ for day of year $98-100($ period 3$)$

\begin{tabular}{lllllll}
\hline$c_{p} / u_{*}$ & $\begin{array}{l}>45 \\
(n=7)\end{array}$ & $\begin{array}{l}40-45 \\
(n=11)\end{array}$ & $\begin{array}{l}35-40 \\
(n=18)\end{array}$ & $\begin{array}{l}25-35 \\
(n=52)\end{array}$ & $\begin{array}{l}15-25 \\
(n=98)\end{array}$ & $\begin{array}{l}10-20 \\
(n=8)\end{array}$ \\
\hline$A\left[\mathrm{~m}^{-1}\right]$ & $>50$ & 50 & 5.0 & 0.5 & 1.0 & 0.5 \\
$<R>(\%)$ & $>50$ & 18 & 6 & 4 & 7 & 3 \\
\hline
\end{tabular}

estimates (Tables 1, 2 and 3). The energy closure works well for the bin-averaged data in the $15<c_{p} / u_{*}<35$ range for all three periods in question (Fig. 7).

During conditions leading to old seas (i.e. $c_{p} / u_{*}>40$ ) the reduction in the error reported in Tables 1, 2 and 3 was not further possible as large changes in the decay rate have little significant effect in the energy estimates. This leads to large overestimations of the wind input, relative to the spectral estimates. For younger seas (i.e. $10<c_{p} / u_{*}<35$ ) this approach gives good closure (within 10\%) although the sensitivity to changes in the decay rate was difficult to ascertain due to limited number of data points.

\subsection{The Wave-Boundary-Layer Height and the Characteristic Phase Speed}

In this section, we estimate a characteristic phase speed $\left(c_{w}\right)$ that we associate with the phase speed of the wind-driven waves that are most strongly coupled with the wind stress. To assist in this investigation, we use the approach described by Terray et al. (1996) to estimate the energy flux using an "effective phase speed" $\bar{c}$ as

$$
F=\rho_{w}\left(u_{*}^{w}\right)^{2} \bar{c}
$$

where $u_{*}^{w}$ is the water friction velocity and the relationship between the atmospheric and ocean friction velocities is given by $\rho_{a}\left(u_{*}^{a}\right)^{2} \approx \rho_{w}\left(u_{*}^{w}\right)^{2}$, where $\rho_{w}$ is the water density and 


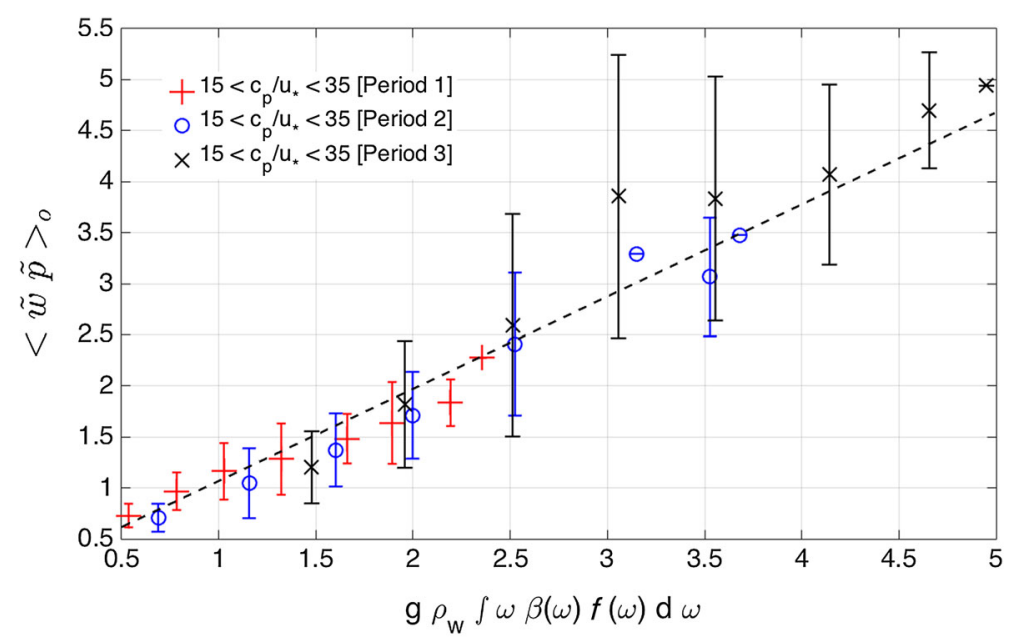

Fig. 7 Bin-averaged energy balance across the WBL for all periods under consideration based on the Snyder et al. (1981) wave-growth parametrization (Eq. 20). The estimates reported here were further constrained for a wave age: $15 \leq c_{p} / u_{*} \leq 35$, the black plus signs correspond to period 1 , the black circles correspond to period 2 and the $\mathrm{X}$ marker denotes period 3 . The error bars account for one standard deviation and both axes have units of $\mathrm{W} \mathrm{m}^{-2}$

$u_{*}^{a}$ is the atmospheric friction velocity (stated simply as $u_{*}$ throughout). The $F$ term on the 1.h.s. of Eq. 25 is simply the energy flux to the wave, analogous to Eq. 19, i.e.

$$
F=\rho_{a}\left(u_{*}^{a}\right)^{2}=\rho_{a}\langle\tilde{u} \tilde{w}\rangle_{o} \int_{z_{o}}^{Z} \frac{\partial U^{l}}{\partial z} \exp (-A z) \mathrm{d} z .
$$

This relationship suggests that we can define a characteristic phase speed as

$$
c_{w}=\int_{z_{o}}^{Z} \frac{\partial U^{l}}{\partial z} \exp (-A z) \mathrm{d} z
$$

where the contribution of the viscous stress has been ignored for simplicity. Finally, we introduce a third approach to the estimate of the characteristic phase speed based on the assumption that the WBL height is inversely proportional to a characteristic wavenumber (e.g., Chalikov 1995). Here we use the estimates of the decay rate $A$ to calculate a height at which $10 \%$ of the total stress is supported by the waves (i.e. $\left.\langle\tilde{u} \tilde{w}\rangle_{o} \exp \left(-A z_{w b l}\right) /\left(u_{*}\right)^{2}=0.1\right)$. We use this height to determine the effective wavenumber $\left(k_{w b l}\right)$ assuming the relation: $z_{w b l}$ $=1 / k_{w b l}$. The effective wavenumber is then used with the deep-water dispersion relationship to estimate another characteristic phase speed given by $c_{w b l}=\sqrt{g / k_{w b l}}$. This definition effectively sets $\alpha=1$ as a proportionality coefficient.

Table 4 shows the averaged estimates of the characteristic phase speed for all three methods and for all periods under consideration. The estimates of the phase speeds given by Eqs. 23 and 25 shown in Table 4 are within 5\% and reflect a trend of larger (i.e. faster) characteristic wave scales for younger seas. The estimates based on the height of the WBL, $c_{w b l}$, appear to underestimate the phase speed for old seas.

The values of $c_{w b l}$ for younger seas follow from a near-constant value of the decay rate (A) under a wide variety of conditions for $c_{p} / u_{*}<35$ (see Tables 1, 2 and 3). The behaviour of $c_{w} / c_{p}$ for individual periods is plotted in Fig. 8a using $c_{w}$ from Eq. 25. The ratio $c_{w} / c_{p}$ is compared against the approximate behaviour of $\bar{c} / c_{p}$ from Terray et al. (1996) from their 
Table 4 Estimates of the average characteristic phase speed

\begin{tabular}{lllll}
\hline$c_{p} / u_{*}$ & $35-40$ & $25-35$ & $15-25$ & $10-20$ \\
\hline$c_{w}\left[\mathrm{~m} \mathrm{~s}^{-1}\right]$ & $2.86 \pm 0.14$ & $3.30 \pm 0.18$ & $3.69 \pm 0.19$ & $4.10 \pm 0.42$ \\
$\bar{c}\left[\mathrm{~m} \mathrm{~s}^{-1}\right]$ & $2.61 \pm 0.16$ & $3.30 \pm 0.32$ & $3.59 \pm 0.30$ & $3.87 \pm 0.46$ \\
$c_{w b l}\left[\mathrm{~m} \mathrm{~s}^{-1}\right]$ & $1.41 \pm 0.62$ & $5.41 \pm 1.13$ & $5.41 \pm 1.13$ & $6.06 \pm 1.13$ \\
\hline
\end{tabular}

Here, $\bar{c}$ follows from the Terray et al. (1996) method using the SO GasEx data, $c_{w}$ is the characteristic phase speed defined in Eq. (25), and $c_{w b l}$ follows from the assumption: $z_{w b l}=1 / k_{w}$

lake experiment (i.e. their Fig. 6) as shown by the solid black line in Fig. 8a. Hexagrams, squares and circles show the bin-averaged results for periods 1, 2 and 3 respectively.

The black dot-dashed line is a linear least-squares fit to the all data where the model is as stated in Eq. 28 and the parameters to solve are $\Gamma$ and $n$. The solid grey line is a linear least-squares fit to all data, where the model used in this case is stated in Eq. 30, and where we solve for $b_{o}$ and $m$,

$$
\frac{c_{w}}{c_{p}}=\Gamma\left(\frac{u_{*}}{c_{p}}\right)^{n},
$$

where $\Gamma$ and $n$ are constant coefficients of the power law in Eq. 28. The regression for Eq. 29 based on all the bin-averaged $c_{w}$ data yields values for $\Gamma$ and $n$ as 1.42 and 0.59 , respectively (Fig. 8a). The solid grey line is a linear least-squares fit to all data assuming a linear relationship,

$$
\frac{c_{w}}{c_{p}}=b_{o}+\mathrm{m}\left(\frac{u_{*}}{c_{p}}\right),
$$

where $b_{o}$ and $m$ are simply the intercept and slope of the fit, where the coefficients $b_{o}$ and $m$ are calculated as 0.075 and 3.43 (Fig. 8a). Figure $8 \mathrm{~b}$ shows the behaviour of $c_{w b l} / c_{p}$ as a function of inverse wave age as shown by the diamonds; fitting Eq. 28 to the $c_{w b l}$ estimates yields a quadratic behaviour (Fig. 8b). The coefficients $\Gamma$ and $n$ for this case are estimated to be 240 and 2.20 respectively (dashed black line Fig. 8b). We find this behaviour is inconsistent with Terray et al. (1996); i.e., it does not plateau (or roll over) for young developing seas, where in order to observe any saturation we expect $n<1$ in Eq. 28. Fitting of Eq. 29 yielded the coefficients $b_{o}$ and $m$ to be -0.13 and 8.8 respectively, which is more consistent with Terray et al. (1996) for $0.02 \leq u_{*} / c_{p} \leq 0.75$ (Fig. 8b). For comparison, the bin-average of all data shown in Fig. $8 \mathrm{a}$ is given by the grey squares in Fig. $8 \mathrm{~b}$.

\section{Discussion}

Under strong forcing (i.e. $c_{p} / u_{*}<35$ ), the energy balance between wind input and the proposed extraction mechanism closes the energy balance across the WBL within $10 \%$ and predicts a decay rate of $0.5-1 \mathrm{~m}^{-1}$. The effective wave speed is found to be consistent with Terray et al. (1996), although the slope of a linear fit to $c_{w} / c_{p}$ from this set of observations is less steep than that of Terray et al. (1996) for older waves (Fig. 8a). Defining the effective wave speed from the scale $k_{w}=1 / z_{w b l}$, and relying on Eq. 30 to perform a linear leastsquares regression we find the ratio $c_{w b l} / c_{p}$ to better fit the Terray et al. (1996) behaviour in the range $0.02 \leq u_{*} / c_{p} \leq 0.75$ (Fig. $8 \mathrm{~b}$ ). 

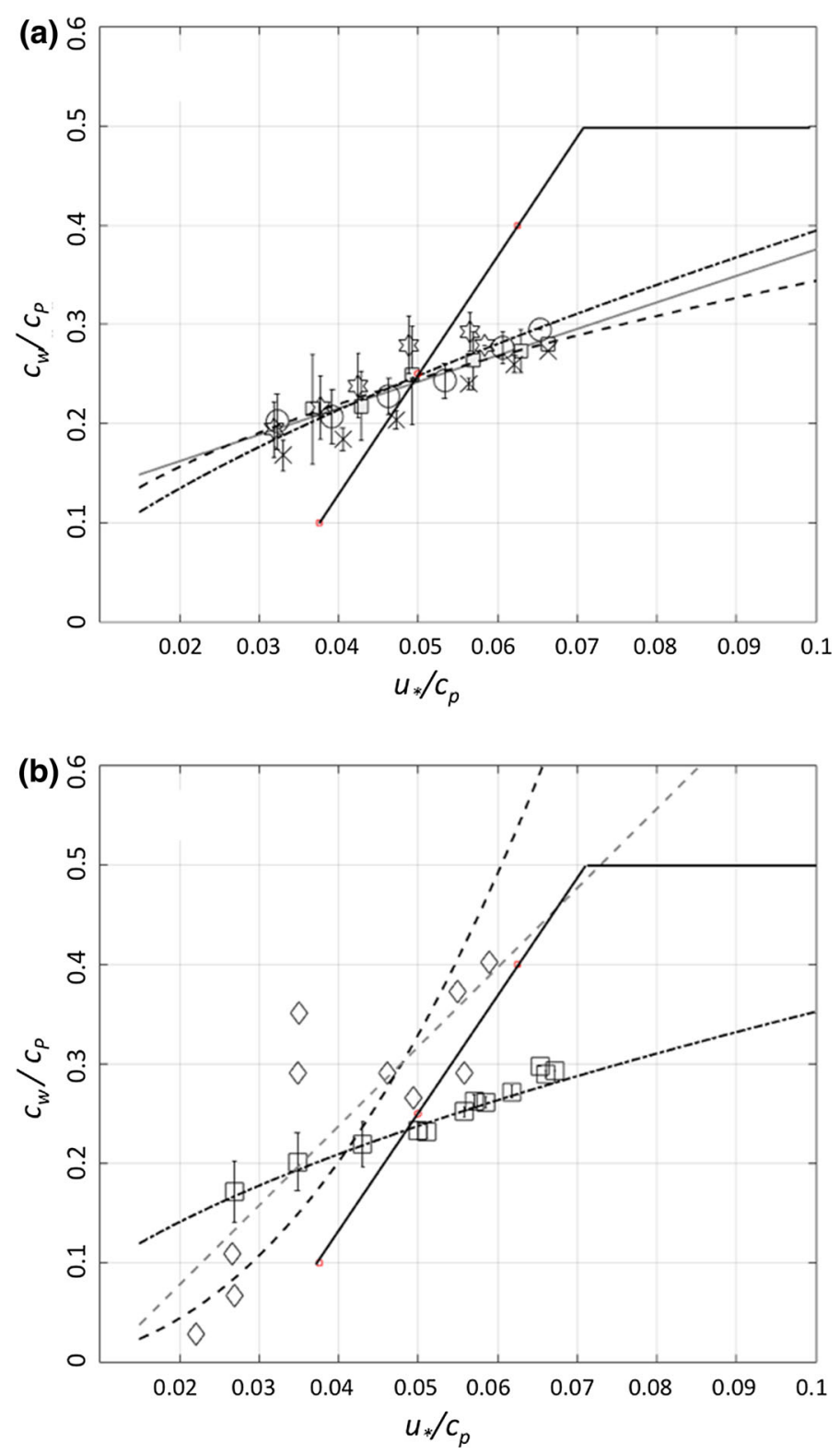

Fig. 8 Ratio $c_{w} / c_{p}$ of the effective phase speed $\left(c_{\mathrm{W}}\right)$ to the peak phase speed as a function of forcing $u_{*} / c_{p} ; \mathbf{a}$ bin-averaged data shown in black hexagrams correspond to period 1 and black squares to period 2 and the black circle to period 3. Solid black line shows the approximate behaviour of $c_{w} / c_{p}$ as a function of $u_{*} / c_{p}$ presented in Terray et al. (1996). The black dot-dashed line is a linear least-squares fit to the all data (Eq. 28).Solid grey line is a linear least squares fit to all data assuming a linear behaviour (Eq. 29). b Shows the ratio $c_{w} / c_{p}$ as a function of $u_{*} / c_{p}$ where $c_{w}$ follows from: $k_{w}=1 / z_{w b l}$. This is shown in black diamonds. Grey squares represent a bin average of all data presented on Fig. 8a. The black dot-dashed line is a linear least-squares fit to the grey squares (Eq. 28). The dashed grey line is a linear least squares fit to the black diamonds assuming the parametrization stated in Eq. 29 and the black dashed line corresponds to the fit based on Eq. 28 
The investigation of Terray et al. (1996) was based primarily on lake data where the observed characteristic phase speed was approximately half of the peak phase speed for very young waves, i.e., $c_{w}=0.5 c_{p}$. However, the results for older seas suggest that the characteristic phase speed (and wavelength) decreases with decreasing stress, suggesting that increasingly shorter wind-waves support the wave-induced energy and momentum flux as the wind speed decreases, until viscous stress is largely responsible for the exchange. Of course this depends on the value of $c_{p}$ at a given stress, so the simple statement is complicated by whether the peak waves are locally driven or represent swell at these inverse wave ages. It is also possible that the equilibrium condition $c_{w} / c_{p} \approx 0.5$ suggested by Terray et al. (1996) may not be applicable to open ocean conditions (i.e. in the presence of non-locally generated waves or swell) or at least exhibits a slower transition.

From the decay rates, we have estimated a WBL height of 1-3 m under open ocean conditions, where the WBL was set as the height at which $10 \%$ of the total momentum flux is still supported by waves. This is consistent with previous theoretical work (e.g., Makin and Mastenbroek 1996). These estimates indicate that MOST remains valid as long as measurements are made at $z>z_{w b l}$ and is generally satisfied as long as the measurements are made above $4 \mathrm{~m}$. These results were derived for a mature to growing scenario with the goal of determining open-ocean wave scales actively coupled with the wind forcing. The method proposed here fails in the presence of old seas; we cannot provide an estimate of the height of the WBL under such conditions, perhaps as a consequence of a change in local kinematics, such as a wave-induced momentum-flux divergence in the WBL modifying the shear structure (e.g., Sullivan et al. 2008), rendering our local assumptions invalid.

Finally, based on our observations and the assumptions behind the wind-wave coupling model, we recommend the use of Eq. 29 with $\Gamma=1.42$ and $n=0.59$ to provide an openocean effective phase-speed parametrization. Although, the transition to saturation appears to be lower than the transition presented by Terray et al. (1996), the effective wave speed is consistent with the Terray et al. (1996) approach (Table 4). This parametrization could be used to estimate the energy flux into the wave field from the atmospheric friction velocity and peak phase speeds. Further observations under open ocean conditions during a wide range of forcing conditions are needed to test the $c_{w} / c_{p}$ parametrizations derived from Eqs. 29 and 30 .

\section{Conclusions}

We have conducted a marine surface-layer study that relies on a momentum and energy balance at the air-sea interface. At the air-sea interface, the total surface stress is fully supported by form drag (normal stress) and viscous (or tangential) stress. An estimate of the wave-induced momentum flux (i.e., the form drag) is found from direct estimates of the total momentum flux after removal of the viscous component at the interface. The viscous stress was computed from a modified version of the Kudryavtsev and Makin (2001) parametrization by matching $U\left(\delta_{v}\right) / u_{*}^{v}$ with the normalized wind speed from the logarithmic profile at the height of the viscous sublayer $\left(z=\delta_{\mathrm{v}}\right)$. The viscous stress is found to have a maximum contribution of approximately $5 \%$ of the total stress at the interface. This estimate of the momentum supported by surface waves is found to agree best with a wave-spectral estimate using the wave-growth parameter given by the wave-growth parametrization of Snyder et al. (1981). 
From the momentum closure at the interface we performed an investigation of the vertical structure of the WBL based on an exponential behaviour. We defined a dimensional decay rate $A=\alpha k$ in order to avoid an a priori definition of the dimensionless decay rate $\alpha$. The wave-spectral observations are then combined with the wave-growth parameter given by Snyder et al. (1981) to estimate the wind-driven energy of the wave field. These estimates are then equated to the modelled atmospheric extraction mechanism given by Eq. 20, which relies on the above-mentioned exponential decay of the wave-induced momentum flux.

The atmospheric extraction mechanism is modified to account for wave-induced perturbations on the airflow by including a local friction velocity within the WBL. This allowed the selection of a decay rate, $A$, that satisfied the energy balance across the WBL. The selection of the decay rate is solved iteratively by minimizing the fractional error. Under conditions of weak atmospheric forcing and old seas, the energy-balance approach used in this investigation only allowed closure within $35 \%-50 \%$. We have hypothesized that this is due to an upward ocean-atmosphere momentum flux not accounted for with our exponential decay, together with other factors such as larger flux uncertainties at low wind speeds and directional differences between the wind and swell field.

Despite the limitations of this bulk approach to the momentum balance across the WBL the one-dimensional energy balance reveals an effective wave scale $1 / A$, which corresponds to the longest wave scale actively coupled with the wind, where $A$ is the decay rate of the wave-induced momentum flux. The energy-balance approach developed for this investigation works best for wave ages in the range $c_{p} / u_{*}<35$, a result that is used to approximate the WBL height as the height to which the wave-induced flux is $10 \%$ of its surface value. The WBL height determined this way is found to be $1-3 \mathrm{~m}$. Under open ocean conditions, MOST is expected to hold for measurements above $4 \mathrm{~m}$, although this could potentially vary (become higher) under very strong forcing, with a wave-induced signal reaching higher into the boundary layer.

Acknowledgements This material is based upon work supported by the National Science Foundation under Grant 0647475, the National Oceanic and Atmospheric Administration under Grant NA07OAR4310084, and the NOAA Office of Climate Observations. Additional support was provided by the National Science Foundation (0647667; Christopher Zappa at Lamont Doherty Earth Observatory). This is Lamont-Doherty Earth Observatory contribution number 8219 . Finally, we would like to thank the anonymous reviewers for their constructive criticism and helpful comments during the review process.

\section{References}

Anis A, Moum JN (1995) Surface wave-turbulence interactions. Scaling E(z) near the sea surface. J Phys Oceanogr 25(9):2025-2045

Belcher SE, Hunt JCR (1993) Turbulent shear flow over slowly moving waves. J Fluid Mech 251:109-148. https://doi.org/10.1017/S0022112093003350

Brumer SE, Zappa CJ, Blomquist BW, Fairall CW, Cifuentes-Lorenzen A, Edson JB, Huebert BJ (2017) Wave-related Reynolds number parameterizations of CO2 and DMS transfer velocities. Geophys Res Lett 44:9865-9875. https://doi.org/10.1002/2017GL074979

Burgers G, Makin VK (1993) Boundary-layer model results for wind-sea growth. J Phys Oceanogr 23:372-385

Chalikov DV (1995) The parameterization of the wave boundary layer. J Phys Oceanogr 25:1335-1349

Chalikov D, Belevich M (1993) One-dimensional theory of the wave boundary layer. Boundary-Layer Meteorol 63:65-96

Chalikov DV, Makin VK (1991) Models of the wave boundary layer. Boundary-Layer Meteorol 56(1-2):83-99

Chalikov DV, Rainchik S (2011) Coupled numerical modelling of wind and waves and the theory of the wave boundary layer. Boundary-Layer Meteorol 138(1):1-41 
Cifuentes-Lorenzen A, Edson JB, Zappa CJ, Bariteau L (2013) A multisensor comparison of ocean wave frequency spectra from a research vessel during the Southern Ocean Gas Exchange Experiment. J Atmos Ocean Technol 30(12):2907-2925. https://doi.org/10.1175/JTECH-D-12-00181.1

Dobson FW (1971) Measurements of atmospheric pressure on wind-generated sea waves. J Fluid Mech 48(1):91-127. https://doi.org/10.1017/S0022112071001496

Donelan MA, Pierson WJ (1987) Radar scattering and equilibrium ranges in wind-generated waves with application to scatterometry. J Geophys Res 92(C5):4971-5029. https://doi.org/10.1029/JC092iC05p04 971

Donelan MA, Babanin AV, Young IR, Banner ML (2006) Wave-follower field measurements of the wind-input spectral function. Part II: parameterization of the wind input. J Phys Oceanogr 36(8):1672-1689

Drennan WM, Donelan MA, Terray EA, Katsaros KB (1996) Oceanic turbulence dissipation measurements in SWADE. J Phys Oceanogr 26(5):808-815. 10.1175/1520-0485(1996)026<0808:OTDMIS>2.0.CO;2

Drennan WM, Graber HC, Hauser D, Quentin C (2003) On the wave age dependence of wind stress over pure wind seas. J Geophys Res 108(C3):8062. https://doi.org/10.1029/2000JC000715

Edson JB, Fairall CW (1998) Similarity Relationships in the marine atmospheric surface layer for terms in the TKE and scalar variance budgets. J Atmos Sci 55(13):2311-2328. 10.1175/15200469(1998)055<2311:SRITMA >2.0.CO;2

Edson JB, Crawford T, Crescenti J, Farrar T, Frew N, Gerbi G, Helmis C, Hristov TS, Khelif D, Jessup A (2007) The coupled boundary layers and air-sea transfer experiment in low winds. Bull Am Meteorol Soc 88(3):341-356

Edson JB, Fairall CW, Bariteau L, Zappa CJ, Cifuentes-Lorenzen A, McGillis WR, Pezoa S, Hare JE, Helmig D (2011) Direct covariance measurement of $\mathrm{CO}_{2}$ gas transfer velocity during the 2008 Southern Ocean Gas Exchange Experiment: wind speed dependency. J Geophys Res 116:C00F10. https://doi.org/10.10 29/2011jc007022

Edson JB, Jampana V, Weller RA, Bigorre SP, Plueddemann AJ, Fairall CW, Miller SD, Mahrt L, Vickers D, Hersbach H (2013) On the exchange of momentum over the open ocean. J Phys Oceanogr 43(8):1589-1610. https://doi.org/10.1175/JPO-D-12-0173.1

Finnigan JJ, Einaudi F, Fua D (1984) The interaction between an internal gravity wave and turbulence in the stably-stratified nocturnal boundary layer. J Atmos Sci 41(16):2409-2436. 10.1175/15200469(1984)041<2409:TIBAIG>2.0.CO;2

Grachev AA, Fairall CW (2001) Upward momentum transfer in the marine boundary layer. J Phys Oceanogr 31(7):1698-1711. 10.1175/1520-0485(2001)031<1698:UMTITM>2.0.CO;2

Grare L, Lenain L, Melville WK (2013) Wave-coherent airflow and critical layers over ocean waves. J Phys Oceanogr 43(10):2156-2172. https://doi.org/10.1175/JPO-D-13-056.1

Hara T, Belcher SE (2004) Wind profile and drag coefficient over mature ocean surface wave spectra. J Phys Oceanogr 34(11):2345-2358. https://doi.org/10.1175/JPO2633.1

Hare JE, Hara T, Edson JB, Wilczak JM (1997) A similarity analysis of the structure of airflow over surface waves. J Phys Oceanogr 27(6):1018-1037

Harris DL (1966) The wave-driven wind. J Atmos Sci 23:688-693. 10.1175/1520-0469(1966)023 $<0688$ :TWDW>2.0.CO;2

Hasselmann D, Bösenberg J (1991) Field measurements of wave-induced pressure over wind-sea and swell. J Fluid Mech 230(1):391-428

Ho DT, Sabine CL, Hebert D, Ullman DS, Wanninkhof R, Hamme RC, Strutton PG, Hales B, Edson JB, Hargreaves BR (2011) Southern Ocean Gas Exchange Experiment: setting the stage. J Geophys Res 116:C00F08. https://doi.org/10.1029/2010jc006852

Högström U, Smedman A, Sahleé E, Drennan WM, Kahma KK, Pettersson H, Zhang F (2009) The atmospheric boundary layer during swell: a field study and interpretation of the turbulent kinetic energy budget for high wave ages. J Atmos Sci 66(9):2764-2779

Högström U, Rutgersson A, Sahlée E, Smedman A-S, Hristov TS, Drennan WM, Kahma KK (2013) Air-sea interaction features in the Baltic Sea and at a Pacific trade-wind site: an inter-comparison study. BoundaryLayer Meteorol 147:139-163. https://doi.org/10.1007/s10546-012-9776-8

Högström U, Sahlée E, Smedman A-S, Rutgersson A, Nilsson E, Kahma KK, Drennan WM (2015) Surface stress over the ocean in swell-dominated conditions during moderate winds. J Atmos Sci 72(12):4777-4795. https://doi.org/10.1175/JAS-D-15-0139.1

Hristov TS, Miller SD, Friehe CA (2003) Dynamical coupling of wind and ocean waves through wave-induced air flow. Nature 422(6927):55-58. https://doi.org/10.1038/nature01382

Janssen PAEM (1989) Wave-induced stress and the drag of air-flow over sea waves. J Phys Oceanogr 19(6):745-754. 10.1175/1520-0485(1989)019<0745:WISATD>2.0.CO;2

Janssen PAEM (1991) Quasi-linear theory of wind-wave generation applied to wave forecasting. J Phys Oceanogr 21(11):1631-1642. 10.1175/1520-0485(1991)021<1631:QLTOWW>2.0.CO;2 
Janssen PAEM (1999) On the effect of ocean waves on the kinetic energy balance and consequences for the inertial dissipation technique. J Phys Oceanogr 29(3):530-534. 10.1175/15200485(1999)029<0530:OTEOOW>2.0.CO;2

Kudryavtsev VN, Makin VK (2001) The impact of air-flow separation on the drag of the sea surface. BoundaryLayer Meteorol 98(1):155-171

Lighthill MJ (1962) Physical interpretation of the mathematical theory of wave generation by wind. J Fluid Mech 14(3):385-398. https://doi.org/10.1017/S0022112062001305

Lombardo CP, Gregg MC (1989) Similarity scaling of viscous and thermal dissipation in a convecting surface boundary layer. J Geophys Res 94(C5):6273-6284. https://doi.org/10.1029/JC094iC05p06273

Makin VK, Kudryavtsev VN (1999) Coupled sea surface-atmosphere model: 1. Wind over waves coupling. J Geophys Res 104(C4):7613-7623

Makin VK, Mastenbroek C (1996) Impact of waves on air-sea exchange of sensible heat and momentum. Boundary-Layer Meteorol 79:279-300

Makin VK, Kudryavtsev VN, Mastenbroek C (1995) Drag of the sea surface. Boundary-Layer Meteorol 73(1):159-182. https://doi.org/10.1007/BF00708935

Mastenbroek C, Makin VK, Garat MH, Giovanangeli JP (1996) Experimental evidence of the rapid distortion of turbulence in the air flow over water waves. J Fluid Mech 318(1):273-302

McBean GA, Elliott JA (1975) The vertical transports of kinetic energy by turbulence and pressure in the boundary layer. J Atmos Sci 32:753-766

Miles JW (1957) On the generation of surface waves by shear flows. J Fluid Mech 3(02):185-204. https://do i.org/10.1017/S0022112057000567

Monin AS, Yaglom AM (1975) Statistical fluid mechanics: mechanics of turbulence. MIT Press, Cambridge

Plant WJ (1982) A relationship between wind stress and wave slope. J Geophys Res Oceans 87(C3):1961-1967

Rieder KF, Smith JA (1998) Removing wave effects from the wind stress vector. J Geophys Res Oceans 103(C1):1363-1374. https://doi.org/10.1029/97JC02571

Scully ME, Trowbridge JH, Fisher AW (2016) Observations of the transfer of energy and momentum to the oceanic surface boundary layer beneath breaking waves. J Phys Oceanogr 46(6):1823-1837

Smedman A-S, Högström U, Sahleé E, Drennan WM, Kahma KK, Pettersson H, Zhang F (2009) Observational study of marine atmospheric boundary layer characteristics during swell. J Atmos Sci 66(9):2747-2763. https://doi.org/10.1175/2009JAS2952.1

Snyder RL, Dobson FW, Elliott JA, Long RB (1981) Array measurements of atmospheric pressure fluctuations above surface gravity waves. J Fluid Mech 102:1-59. https://doi.org/10.1017/S0022112081002528

Sullivan PP, Edson JB, Hristov T, McWilliams JC (2008) Large-eddy simulations and observations of atmospheric marine boundary layers above nonequilibrium surface waves. J Atmos Sci 65(4):1225-1245

Terray EA, Donelan MA, Agrawal YC, Drennan WM, Kahma KK, Williams AJ, Hwang PA, Kitaigorodskii SA (1996) Estimates of kinetic energy dissipation under breaking waves. J Phys Oceanogr 26(5):792-807. 10.1175/1520-0485(1996)026<0792:EOKEDU>2.0.CO;2

Weber JEH (2008) A note on mixing due to surface wave breaking. J Geophys Res 113(C11):C11009. https:// doi.org/10.1029/2008JC004758

Wetzel S (1996) An investigation of wave-induced momentum flux through phase averaging of open ocean wind and wave fields. Thesis, Massachusetts Institute of Technology, Massachusetts, USA

Willmott CJ, Ackleson SG, Davis RE, Feddema JJ, Klink KM, Legates DR, O’Donnell J, Rowe CM (1985) Statistics for the evaluation and comparison of models. J Geophys Res 90(C5):8995-9005. https://doi.o $\mathrm{rg} / 10.1029 / \mathrm{JC} 090 \mathrm{iC} 05 \mathrm{p} 08995$

Wu L, Rutgersson A, Nilsson E (2017) Atmospheric Boundary layer turbulence closure scheme for windfollowing swell conditions. J Atmos Sci 74(7):2363-2382. https://doi.org/10.1175/JAS-D-16-0308.1

Wyngaard JC, Coté OR (1971) The budgets of turbulent kinetic energy and temperature variance in the atmospheric surface layer. J Atmos Sci 28(2):190-201

Zappa CJ, Farrar JT, Straneo F, Moffat CF (2012) Observations of upper-ocean turbulence during the VOCALS Experiment. Ocean Sciences Meeting, American Geophysical Union, 20-25 February 2012, Salt Lake City, UT, USA 